\title{
Trend and predictors of change of unmet need for family planning among reproductive age group women in Ethiopia, based on Ethiopian demographic and health survey from 2005-2016: Multivariate decomposition analysis
}

Abiyu Abadi Tareke

west Armachiho district health office, Ethiopia

Ermias Bekele ( $\nabla$ ermiashi@gmail.com )

metu university department of health informatics

Research Article

Keywords: Welkait\#2012, family planning, Ethiopia

Posted Date: April 23rd, 2021

DOI: https://doi.org/10.21203/rs.3.rs-443019/v1

License: (c) (1) This work is licensed under a Creative Commons Attribution 4.0 International License.

Read Full License 


\section{Abstract}

Background: Family planning is a key method for reducing population growth and improving maternal and child health by spacing births and preventing unwanted pregnancies. have an unmet need for family planning is defined as women believed to be sexually involved but are not using some form of contraception, either do not want to have more children (Limiting) or want to delay their next birth for at least two years, (Spacing).

Methods: The data for this study arrived from the Ethiopia Demographic Health Surveys (EDHS) in20005, 2011, and 2016 to investigate trends and Predictors of change of unmet need for family planning among reproductive age women in Ethiopia. A pooled weighted sample of 26,230 (7,761 in EDHS 2005, 9,136 in EDHS 2011 and 9,333 in EDHS 2016) reproductive-age women used for this study. For the overall trend (2005-2016) multivariate decomposition analysis for non-linear response outcome was calibrated to identify the factors contributed to the change of unmet need for family planning across the two surveys. The Logit based multivariate decomposition analysis utilizes the output from the logistic regression model to assign the observed change in in unmet need for family planning over time into components. Stata version 16.0 was used to analysis the data.

Result: among reproductive age women in Ethiopia the magnitude of unmet need for family planning decreased from $39.6 \%$ in 2005 to $23.6 \%$ in 2016 . From the decomposition analysis change of unmet need for family planning was due to change in characteristics and coefficients. About nine in ten changes in unmet need for family planning was attributable to the difference in coefficients. Factors that associated with the change of unmet need for family planning over the last 11 years were educational status, birth order, and desired number of children.

Conclusion: Remarkable change in unmet need for FP was observed between the period of 2005 and 2016. Both change in characteristics and coefficient were the contributing to observed change. Majority of the change in unmet need for FP was due to difference in coefficient over the study period. Mainly the change of unmet need for FP was due to change in women having birth order of five and above, having secondary education and women who desired number of children below five.

\section{Introduction}

\subsection{Background}

Family planning is a key method for reducing population growth and improving maternal and child health by spacing births and preventing unwanted pregnancies (1). Both fecund reproductive-age women who are married and in consensual marriage have an unmet need for family planning and believed to be sexually involved but are not using some form of contraception, either do not want to have more children (Limiting) or want to delay their next birth for at least two years, (Spacing) $(2,3)$. 
In 2015, globally unmet need for family planning among married women were 12 percent(4). In a developing country approximately 225 million people had an unmet need for modern contraception. Of this number, 160 million were using no method and 65 million were using a traditional method and an estimated 74 million unintended pregnancies occur annually, 52 million of these premature births could be avoided, saving 70,000 women from pregnancy-related death in 2014.(5)

Unmet need for family planning among married or in union women of reproductive age in Sub-Saharan Africa was $25 \%$, posing a major public health concern $(6,7)$. In Burkina Faso, Malawi, Cameroon, and Ghana the prevalence of unmet need for family planning among reproductive age group women was $18.3 \%, 21.0 \%, 46.6 \%$, and $38.9 \%$ respectively (8-11). In Ethiopia according to an Ethiopian demographic and health survey, unmet FP needs fell from $37 \%$ in 2000 to $22 \%$ in 2016(12).

Respective researchers have examined at various factors that influence women's unmet need for family planning, such as age, parity, and religion (13), Discussions with partners and wellness extension staff, as well as awareness of contraceptive methods (14), A visit to a health center, media exposure, a husband and wife's educational status, and residence (15), Due to contraception-related factors like availability, accessibility, affordability, and side effects, there is an unmet need (16), early marriage, wealth index (17), Number of children alive, use of contraceptive methods(18), partner's attitude toward the use of family planning, current menstrual status, healthcare providers visit and discussion about family planning issues(19).

Unmet family planning needs can have serious consequences for women and their families, including illegal abortion, physical violence, and a high fertility rate linked to poverty and poor maternal and child health $(20,21)$. Though, improving family planning (FP) access is fundamental for sustainable development goal (SDG) achievement. It is linked to human rights, gender equality and women's empowerment and has an impact on maternal, newborn, child and adolescent health.

Different researchers in Ethiopia have identified the prevalence and determinant factors of unmet family planning needs., as far as my literature searching, studies concerning on the trends and identify the contributing factors for the change in unmet need for family planning in Ethiopia over the studying period among reproductive age group women are limited.

Using multivariate decomposition analysis to identify the significant factors that affect the unmet need for family planning for contributing the change in unmet need for family planning over time that have become important to targeting on factors that decreasing unmet need for family planning and to forward policies and programs that focusing on reducing of unmet need for family planning in Ethiopia.

Therefore, this study is aimed to address the trends and contributing factors for change in unmet need for family planning over time by using multivariate decomposition analysis based on the 2005-2016 Ethiopian Demographic and Health Survey (EDHS).

\section{Method And Materials}




\section{Study design and sampling procedures}

The data for this study arrived from the Ethiopia Demographic Health Surveys (EDHS) in20005, 2011, and 2016 to investigate trends and Predictors of change of unmet need for family planning among reproductive age women in Ethiopia. In each of the surveys, a two-stage cluster sampling was employed. In the first stage, 540 Enumeration Areas (EAs) for EDHS 2005, 624 EAs for EDHS 2011, and 645 EAs for EDHS 2016 were randomly selected proportional to the EA size and, on average, 27 to 32 households per EAs were selected in the second stage. A pooled weighted sample of 26,230 (7,761 in EDHS 2005, 9,136 in EDHS 2011 and 9,333 in EDHS 2016) reproductive-age women used for this study. The detailed information about sampling procedures was presented in the EDHS report(12, 22).

\section{Study Variables}

\section{Outcome variable}

The outcome variable was the unmet need for FP, where it composed of unmet need for spacing and limiting form of unmet need. It refers to the proportion of women who desire to either delay the next pregnancy or limit future pregnancies but are not using any method of modern contraception(11). And categorized as women with unmet need for spacing and limiting were 'unmet need' and coded as 1 , while those using FP methods for spacing or limiting or with no unmet need were 'met need' coded as 0.

\section{Independent variables}

The independent variables included in this study were: maternal age, women educational status, religion, husband education status, marital status, place of residence, women working status, husband working status wealth index, media exposure, pregnancy termination, knowledge about family planning, visited health facility last 12 months, visited by felid worker, perceived distance to health facility and desired number of children.

\section{Statistical Analysis}

Important variables were extracted from the Individual Record (IR) datasets. Data were weighted using "svyset" STATA command and it was applied for descriptive analysis. The variables required for the "svyset" is the weight variable (v005), primary sampling unit (v021), and strata (v023). Trend analysis of unmet need for family planning and decomposition of the decrease in the prevalence of unmet need for family planning over time was done.The trend analysis has been done by separating based on time period as (2005-20011), (2011-2016) and the overall trend (2005-2016). 
For the overall trend (2005-2016) multivariate decomposition analysis for non-linear response outcome was calibrated to identify the factors contributed to the change of unmet need for family planning across the two surveys. For our study, Logit based decomposition analysis was employed. The Logit based multivariate decomposition analysis utilizes the output from the logistic regression model to assign the observed change in in unmet need for family planning over time into components.

For our study, the 2016 EDHS data was appended to the 2005 EDHS data using the "append" Stata command, and the Logit based multivariate decomposition analysis (using mvdcmp STATA command) was used to identify factors that contributed to the decrease in unmet need for family planning over the last 11 years. The decrease in unmet need for family planning can be explained by the compositional difference between surveys (i.e. differences in characteristics) and/or the difference in effects of explanatory variables (i.e. differences in the coefficients) between the surveys. Hence, the observed decrease in unmet need over time is additively decomposed into a compositional difference of respondents of each survey (endowments) component and a coefficient (or effects of characteristics) component.

For logistic regression, the Logit or log-odd of unmet need for family planning is taken as:

\section{Logit (2005)-Logit $(2016)=F(X 2005 \beta 2005)-(F$ X2016ß2016)}

\section{$\frac{[\mathrm{F}(\mathrm{X2005} \beta 2005)-\mathrm{F}(\mathbf{X 2 0 1 6} \boldsymbol{\beta} 2005)]}{\mathrm{E}}+\frac{[\mathrm{F}(\mathrm{X2016} \boldsymbol{\beta} 2005)-\mathrm{F}(\mathbf{X 2 0 1 6 \beta 2 0 1 6})]}{C}$}

X indicates independent variables (unmet need in this study)

$\beta$ denotes that, regression coefficient of each selected explanatory variables

The E component refers to the part of the differential owing to differences in endowments or characteristics. The $\mathrm{C}$ component refers to that part of the differential attributable to differences in coefficients or effects.

Ethical approval and consent

Authors have requested DHS Program through an online request by written letter of objective and significance of the study. Permission for data access was granted to download and use the data from http://www.dhsprogram.com . The EDHS programs permitted data access, and data were used for only the current study.

\section{Result}

\section{Characteristics of the study population}


Table 1 below illustrates Percentage distribution of selected characteristics of respondents in 2005, 2011 and 2016 Ethiopian Demographic and Health Surveys. It is apparent that women age group 25-34 years were the dominant percentage of women across the three successive surveys. Across the three successive surveys, there was a clear trend of decline in percentage of unmet need for spacing (from $25.5 \%$ to $14.34 \%$ ) by 9.16 point percentage and unmet need for limiting (from $16.05 \%$ to $9.22 \%$ ) by $6.83 \%$ point values.

Regarding educational status of the study participants, women with no education decreased by $17.2 \%$ in 11 years. However, the number of women with primary school and those with high school and above increased by 12.7 percent and 4.6 percent, respectively. Percentage of orthodox Christian declined from by $1.4 \%$ and $2.4 \%$ from 2005 to 2011 and 2011 to 2016 respectively. Over all the total drop of Christian orthodox was 3.8 point percentage. But, percentage of Protestants and Muslim follower increased by $2.7 \%$ and $2.2 \%$ from 2005 to 2016 surveys.

With respect to wealth status of household scanty change was occurred in Ethiopia between the period of 2005 and 2016. Poorest, poorer, middle and richer shows little decrement ranging from $0.2 \%$ to $1.2 \%$ point values. But, household with the richest category shows some increment by $2.5 \%$. In addition, the proportion of male household head fell by 5.2 percent, while the percentage of female household head rose by $4.8 \%$ percent from 2005 to 2016.

Table 1. Percentage distribution of socio-demographic characteristics among respondents, 2005, 2011 and 2016 EDHS 


\begin{tabular}{|c|c|c|c|c|c|c|}
\hline Characteristics & $\begin{array}{l}2005 \\
\text { EDHS } \\
N=7,761\end{array}$ & $\begin{array}{l}2011 \\
\text { EDHS } \\
N=9,136\end{array}$ & $\begin{array}{l}2016 \\
\mathrm{EDHS} \\
\mathrm{N}=9,333\end{array}$ & $\begin{array}{l}2011- \\
2005\end{array}$ & $\begin{array}{l}2016- \\
2011\end{array}$ & $\begin{array}{l}2016- \\
2005\end{array}$ \\
\hline \multicolumn{7}{|c|}{ Unmet need of family planning } \\
\hline $\begin{array}{l}\text { Unmet need for } \\
\text { spacing }\end{array}$ & $23.5 \%$ & $18.81 \%$ & $14.34 \%$ & $-4.69 \%$ & $-4.47 \%$ & $-9.16 \%$ \\
\hline $\begin{array}{l}\text { Unmet need for } \\
\text { limiting }\end{array}$ & $16.05 \%$ & $10.18 \%$ & $9.22 \%$ & $-5.87 \%$ & $-0.96 \%$ & $-6.83 \%$ \\
\hline Total unmet need & $39.55 \%$ & $29 \%$ & $23.6 \%$ & $-10.6 \%$ & $-5.4 \%$ & $-16 \%$ \\
\hline \multicolumn{7}{|l|}{ Age of respondents } \\
\hline $15-24$ & $28.9 \%$ & $28.2 \%$ & $26.0 \%$ & $-0.7 \%$ & $-2.2 \%$ & $-2.9 \%$ \\
\hline $25-34$ & $43.9 \%$ & $45.2 \%$ & $46.6 \%$ & $1.3 \%$ & $1.4 \%$ & $2.7 \%$ \\
\hline $35+$ & $27.2 \%$ & $26.6 \%$ & $27.4 \%$ & $-0.6 \%$ & $0.8 \%$ & $0.2 \%$ \\
\hline \multicolumn{7}{|l|}{ Region } \\
\hline Tigray & $6.5 \%$ & $6.5 \%$ & $6.8 \%$ & $0.0 \%$ & $0.3 \%$ & $0.3 \%$ \\
\hline Afar & $1.1 \%$ & $1.0 \%$ & $0.9 \%$ & $-0.1 \%$ & $-0.1 \%$ & $-0.2 \%$ \\
\hline Amhara & $25.2 \%$ & $26.3 \%$ & $24.7 \%$ & $1.1 \%$ & $-1.6 \%$ & $-0.5 \%$ \\
\hline Oromia & $36.9 \%$ & $38.2 \%$ & $38.3 \%$ & $1.3 \%$ & $0.1 \%$ & $1.4 \%$ \\
\hline Somali & $3.8 \%$ & $2.2 \%$ & $2.9 \%$ & $-1.6 \%$ & $0.7 \%$ & $-0.9 \%$ \\
\hline Benishangul-gumuz & $1.0 \%$ & $1.2 \%$ & $1.1 \%$ & $0.2 \%$ & $-0.1 \%$ & $0.1 \%$ \\
\hline SNNP & $22.0 \%$ & $19.7 \%$ & $20.5 \%$ & $-2.3 \%$ & $0.8 \%$ & $-1.5 \%$ \\
\hline Gambela & $0.3 \%$ & $0.5 \%$ & $0.3 \%$ & $0.2 \%$ & $-0.2 \%$ & $0.0 \%$ \\
\hline Harari & $0.3 \%$ & $0.3 \%$ & $0.2 \%$ & $0.0 \%$ & $-0.1 \%$ & $-0.1 \%$ \\
\hline Addis Ababa & $2.7 \%$ & $3.9 \%$ & $3.9 \%$ & $1.2 \%$ & $0.0 \%$ & $1.2 \%$ \\
\hline Dire-Dawa & $0.4 \%$ & $0.4 \%$ & $0.5 \%$ & $0.0 \%$ & $0.1 \%$ & $0.1 \%$ \\
\hline \multicolumn{7}{|c|}{ Partner's educational status } \\
\hline No Education & $56.7 \%$ & $46.4 \%$ & $44.4 \%$ & $-10.3 \%$ & $-2.0 \%$ & $-12.3 \%$ \\
\hline Primary & $29.5 \%$ & $41.0 \%$ & $38.1 \%$ & $11.5 \%$ & $-2.9 \%$ & $8.6 \%$ \\
\hline Secondary\& above & $13.2 \%$ & $11.8 \%$ & $16.9 \%$ & $-1.4 \%$ & $5.1 \%$ & $3.7 \%$ \\
\hline Orthodox & $45.9 \%$ & $44.5 \%$ & $42.1 \%$ & $-1.4 \%$ & $-2.4 \%$ & $-3.8 \%$ \\
\hline
\end{tabular}


Religion

$\begin{array}{lllllll}\text { Catholic } & 1.2 \% & 1.0 \% & 0.7 \% & -0.2 \% & -0.3 \% & -0.4 \% \\ \text { Protestant } & 18.9 \% & 22.3 \% & 21.6 \% & 3.4 \% & -0.7 \% & 2.7 \% \\ \text { Muslim } & 31.7 \% & 30.4 \% & 33.9 \% & -1.3 \% & 3.5 \% & 2.2 \% \\ \text { Traditional } & 1.4 \% & 0.9 \% & 1.0 \% & -0.5 \% & 0.2 \% & -0.4 \% \\ \text { Other } & 1.0 \% & 0.9 \% & 0.7 \% & -0.1 \% & -0.2 \% & -0.3 \%\end{array}$

\section{Respondent's educational status}

\begin{tabular}{lllllll} 
No Education & $75.8 \%$ & $61.8 \%$ & $58.6 \%$ & $-14.0 \%$ & $-3.2 \%$ & $-17.2 \%$ \\
\hline Primary & $17.0 \%$ & $30.4 \%$ & $29.7 \%$ & $13.4 \%$ & $-0.7 \%$ & $12.7 \%$ \\
\hline Secondary\& above & $7.2 \%$ & $7.8 \%$ & $11.8 \%$ & $0.6 \%$ & $4.0 \%$ & $4.6 \%$ \\
\hline Wealth status & & & & & & \\
\hline Poorest & $19.3 \%$ & $20.0 \%$ & $19.1 \%$ & $0.7 \%$ & $-0.9 \%$ & $-0.2 \%$ \\
\hline Poorer & $20.6 \%$ & $20.1 \%$ & $20.2 \%$ & $-0.5 \%$ & $0.1 \%$ & $-0.4 \%$ \\
\hline Middle & $21.3 \%$ & $19.6 \%$ & $20.1 \%$ & $-1.7 \%$ & $0.5 \%$ & $-1.2 \%$ \\
\hline Richer & $19.7 \%$ & $18.7 \%$ & $19.1 \%$ & $-1.0 \%$ & $0.4 \%$ & $-0.6 \%$ \\
\hline Richest & $19.1 \%$ & $21.6 \%$ & $21.6 \%$ & $2.5 \%$ & $0.0 \%$ & $2.5 \%$
\end{tabular}

\section{Place of residency}

$\begin{array}{lllllll}\text { Urban } & 11.1 \% & 19.1 \% & 17.0 \% & 8.0 \% & -2.1 \% & 5.9 \% \\ \text { Rural } & 89.0 \% & 80.9 \% & 83.0 \% & -8.1 \% & 2.1 \% & -6.0 \%\end{array}$

\section{Sex of household head}

$\begin{array}{lllllll}\text { Male } & 90.7 \% & 86.3 \% & 85.5 \% & -4.4 \% & -0.8 \% & -5.2 \% \\ \text { Female } & 9.7 \% & 12.7 \% & 14.5 \% & 3.0 \% & 1.8 \% & 4.8 \%\end{array}$

\section{Birth order}

\begin{tabular}{|lllllll|}
\hline $1^{\text {st }}$ & $14.76 \%$ & $16.04 \%$ & $16.67 \%$ & $1.3 \%$ & $0.6 \%$ & $1.9 \%$ \\
\hline $2^{\text {nd }}$ & $14.79 \%$ & $17.15 \%$ & $15.50 \%$ & $2.4 \%$ & $-1.7 \%$ & $0.7 \%$ \\
\hline $3^{\text {rd }}$ & $14.11 \%$ & $14.21 \%$ & $15.06 \%$ & $0.1 \%$ & $0.8 \%$ & $1.0 \%$ \\
\hline $4^{\text {th }}$ & $13.15 \%$ & $12.82 \%$ & $12.91 \%$ & $-0.3 \%$ & $0.1 \%$ & $-0.2 \%$ \\
\hline $5^{\text {th }} \&$ above & $43.19 \%$ & $39.78 \%$ & $39.87 \%$ & $-3.4 \%$ & $0.1 \%$ & $-3.3 \%$ \\
\hline
\end{tabular}




\begin{tabular}{|lllllll|}
\hline$<18$ years & $69.8 \%$ & $64.4 \%$ & $62 \%$ & $-5.4 \%$ & $-2.4 \%$ & $-7.8 \%$ \\
\hline$>=18$ years & $30.2 \%$ & $35.6 \%$ & $38 \%$ & $5.4 \%$ & $2.4 \%$ & $7.8 \%$ \\
\hline Working status & & & & & & \\
\hline Not working & $68.8 \%$ & $43.7 \%$ & $49.25 \%$ & $-25.1 \%$ & $5.6 \%$ & $-19.6 \%$ \\
\hline working & $31.2 \%$ & $56.3 \%$ & $50.75 \%$ & $25.1 \%$ & $-5.6 \%$ & $19.6 \%$ \\
\hline
\end{tabular}

\section{Trend of unmet need}

Over the last three successive demographic health surveys, unmet need of family planning decline from $39.6 \%$ in 2005 to $23.6 \%$ in 2016 almost by 16 percent. Highest rate of decline was observed from 2005 $(39.6 \%)$ to $2011(29 \%)$ i.e. about 10.6 percent of change. $5.4 \%$ point of fall was also noticed from $2011(29 \%)$ to $2016(23.6 \%)$ (Fig 1). Over all a significant change (non over lapping confidence interval) was detected across the three period of study i.e. 2005 to 2011, 2011 to 2016 and 2005 to 2016 EDHS.

Regionally, Oromia showed largest amount of point decline in proportion of unmet need of family planning i.e. 5.6\% decrement. Next to Oromia region, SNNP (by 5\%), followed by Amhara region (4.7\%). Lowest decrease in unmet need was noticed from region; Somali, Benishangul-Gumuz, Harari and Gambella region. But, Addis Ababa and Dire Dawa city administration shows slight increment in unmet need for family planning from 2005 to 2016 . Even though, between 2005 and 2016 the amount of unmet need diminished by 16 percent, but there have been steady decrease of unmet need in urban areas i.e. $0.1 \%$ only. Regarding religion relatively considerable decrease in unmet need for family planning was shown among orthodox, protestant and Muslim followers from 2005 to 2016 by $9 \%, 4 \%$ and $2.2 \%$ respectively. (Table 2)

Table 2: Trends of unmet need for family planning among reproductive age from 2005, 2011 and 2016 EDHS. 


\begin{tabular}{|c|c|c|c|c|c|c|}
\hline Characteristics & $\begin{array}{l}2005 \\
\text { EDHS } \\
N=7,761\end{array}$ & $\begin{array}{l}2011 \\
\text { EDHS } \\
\mathrm{N}=9,136\end{array}$ & $\begin{array}{l}2016 \\
\text { EDHS } \\
N=9,333\end{array}$ & $\begin{array}{l}2011- \\
2005\end{array}$ & $\begin{array}{l}2016- \\
2011\end{array}$ & $\begin{array}{l}2016- \\
2005\end{array}$ \\
\hline \multicolumn{7}{|c|}{ Age of respondents } \\
\hline $15-24$ & $10.5 \%$ & $7.2 \%$ & $4.8 \%$ & $-3.3 \%$ & $-2.4 \%$ & $-5.7 \%$ \\
\hline $25-34$ & $16.8 \%$ & $12.3 \%$ & $10.3 \%$ & $-4.5 \%$ & $-2.0 \%$ & $-6.5 \%$ \\
\hline $35+$ & $12.3 \%$ & $9.5 \%$ & $8.4 \%$ & $-2.9 \%$ & $-1.1 \%$ & $-3.9 \%$ \\
\hline \multicolumn{7}{|l|}{ Region } \\
\hline Tigray & $1.77 \%$ & $1.57 \%$ & $1.21 \%$ & $-0.20 \%$ & $-0.36 \%$ & $-0.56 \%$ \\
\hline Afar & $0.19 \%$ & $0.18 \%$ & $0.17 \%$ & $-0.01 \%$ & $-0.01 \%$ & $-0.02 \%$ \\
\hline Amhara & $8.96 \%$ & $6.81 \%$ & $4.25 \%$ & $-2.15 \%$ & $-2.56 \%$ & $-4.71 \%$ \\
\hline Oromia & $17.63 \%$ & $13.14 \%$ & $12.06 \%$ & $-4.49 \%$ & $-1.08 \%$ & $-5.57 \%$ \\
\hline Somali & $0.55 \%$ & $0.61 \%$ & $0.37 \%$ & $0.06 \%$ & $-0.24 \%$ & $-0.18 \%$ \\
\hline $\begin{array}{l}\text { Benishangul- } \\
\text { Gumuz }\end{array}$ & $0.36 \%$ & $0.34 \%$ & $0.24 \%$ & $-0.02 \%$ & $-0.10 \%$ & $-0.12 \%$ \\
\hline SNNP & $9.60 \%$ & $5.61 \%$ & $4.60 \%$ & $-3.99 \%$ & $-1.01 \%$ & $-5.00 \%$ \\
\hline Gambella & $0.10 \%$ & $0.09 \%$ & $0.07 \%$ & $-0.01 \%$ & $-0.02 \%$ & $-0.03 \%$ \\
\hline Harari & $0.06 \%$ & $0.08 \%$ & $0.05 \%$ & $0.01 \%$ & $-0.02 \%$ & $-0.01 \%$ \\
\hline Addis Ababa & $0.32 \%$ & $0.47 \%$ & $0.43 \%$ & $0.15 \%$ & $-0.04 \%$ & $0.11 \%$ \\
\hline Dire-Dawa & $0.07 \%$ & $0.10 \%$ & $0.11 \%$ & $0.02 \%$ & $0.02 \%$ & $0.04 \%$ \\
\hline \multicolumn{7}{|c|}{ Partner's educational status } \\
\hline No Education & $22.9 \%$ & $14.8 \%$ & $12.1 \%$ & $-8.14 \%$ & $-2.64 \%$ & $10.8 \%$ \\
\hline Primary & $13.0 \%$ & $12.4 \%$ & $9.1 \%$ & $-0.64 \%$ & $-3.25 \%$ & $-3.9 \%$ \\
\hline $\begin{array}{l}\text { Secondary\& } \\
\text { above }\end{array}$ & $3.9 \%$ & $2.0 \%$ & $2.8 \%$ & $-1.9 \%$ & $0.8 \%$ & $-1.2 \%$ \\
\hline \multicolumn{7}{|l|}{ Religion } \\
\hline Orthodox & $16.8 \%$ & $11.1 \%$ & $7.7 \%$ & $-5.7 \%$ & $-3.4 \%$ & $-9.0 \%$ \\
\hline Catholic & $0.6 \%$ & $0.4 \%$ & $0.3 \%$ & $-0.3 \%$ & $-0.1 \%$ & $-0.4 \%$ \\
\hline Protestant & $8.3 \%$ & $6.5 \%$ & $4.3 \%$ & $-1.8 \%$ & $-2.1 \%$ & $-3.9 \%$ \\
\hline Muslim & $12.8 \%$ & $10.6 \%$ & $10.6 \%$ & $-2.3 \%$ & $0.1 \%$ & $-2.2 \%$ \\
\hline
\end{tabular}




\begin{tabular}{|c|c|c|c|c|c|c|}
\hline Traditional & $0.6 \%$ & $0.3 \%$ & $0.4 \%$ & $-0.3 \%$ & $0.1 \%$ & $-0.2 \%$ \\
\hline \multicolumn{7}{|c|}{ Respondent's educational status } \\
\hline No Education & $31.6 \%$ & $19.5 \%$ & $15.4 \%$ & $-12.1 \%$ & $-4.1 \%$ & $-16.2 \%$ \\
\hline Primary & $6.7 \%$ & $8.7 \%$ & $6.6 \%$ & $2.0 \%$ & $-2.0 \%$ & $0.0 \%$ \\
\hline $\begin{array}{l}\text { Secondary\& } \\
\text { above }\end{array}$ & $1.3 \%$ & $0.9 \%$ & $1.5 \%$ & $-0.4 \%$ & $0.7 \%$ & $0.3 \%$ \\
\hline \multicolumn{7}{|l|}{ Wealth status } \\
\hline Poorest & $7.5 \%$ & $7.0 \%$ & $5.3 \%$ & $-0.5 \%$ & $-1.7 \%$ & $-2.2 \%$ \\
\hline Poorer & $9.2 \%$ & $6.2 \%$ & $5.7 \%$ & $-3.0 \%$ & $-0.5 \%$ & $-3.5 \%$ \\
\hline Middle & $9.1 \%$ & $6.5 \%$ & $5.0 \%$ & $-2.6 \%$ & $-1.5 \%$ & $-4.1 \%$ \\
\hline Richer & $8.5 \%$ & $5.8 \%$ & $4.3 \%$ & $-2.7 \%$ & $-1.5 \%$ & $-4.2 \%$ \\
\hline Richest & $5.2 \%$ & $3.6 \%$ & $3.2 \%$ & $-1.7 \%$ & $-0.4 \%$ & $-2.0 \%$ \\
\hline \multicolumn{7}{|c|}{ Place of residency } \\
\hline Urban & $2.1 \%$ & $3.2 \%$ & $2.1 \%$ & $1.0 \%$ & $-1.1 \%$ & $-0.1 \%$ \\
\hline Rural & $37.4 \%$ & $25.9 \%$ & $21.5 \%$ & $-11.5 \%$ & $-4.4 \%$ & $-16.0 \%$ \\
\hline \multicolumn{7}{|c|}{ Sex of household head } \\
\hline Male & $36.0 \%$ & $25.2 \%$ & $20.0 \%$ & $-10.8 \%$ & $-5.1 \%$ & $-16.0 \%$ \\
\hline Female & $3.6 \%$ & $3.8 \%$ & $3.5 \%$ & $0.3 \%$ & $-0.3 \%$ & $0.0 \%$ \\
\hline \multicolumn{7}{|l|}{ Birth order } \\
\hline $1^{\text {st }}$ & $4.8 \%$ & $3.3 \%$ & $2.4 \%$ & $-1.5 \%$ & $-0.9 \%$ & $-2.4 \%$ \\
\hline $2^{\text {nd }}$ & $4.5 \%$ & $3.8 \%$ & $2.6 \%$ & $-0.7 \%$ & $-1.2 \%$ & $-2.0 \%$ \\
\hline $3^{\text {rd }}$ & $5.7 \%$ & $3.5 \%$ & $2.9 \%$ & $-2.2 \%$ & $-0.6 \%$ & $-2.8 \%$ \\
\hline $4^{\text {th }}$ & $5.0 \%$ & $3.5 \%$ & $2.9 \%$ & $-1.4 \%$ & $-0.7 \%$ & $-2.1 \%$ \\
\hline $5^{\text {th }} \&$ above & $20.4 \%$ & $15.6 \%$ & $13.8 \%$ & $-4.8 \%$ & $-1.7 \%$ & $-6.6 \%$ \\
\hline \multicolumn{7}{|c|}{ Age at first marriage } \\
\hline$<18$ years & $11.8 \%$ & $8.9 \%$ & $7.9 \%$ & $-2.9 \%$ & $-1.0 \%$ & $-3.9 \%$ \\
\hline$>=18$ years & $28.1 \%$ & $20.2 \%$ & $15.7 \%$ & $-7.8 \%$ & $-4.5 \%$ & $-12.3 \%$ \\
\hline \multicolumn{7}{|l|}{ Working status } \\
\hline Not working & $12.0 \%$ & $15.8 \%$ & $11.3 \%$ & $3.8 \%$ & $-4.5 \%$ & $-0.7 \%$ \\
\hline
\end{tabular}


Additionally, there was decrease in magnitude of unmet need for family planning in women's who had no education from 2005 to 2016 at $16.2 \%$ point percentage decrement. On the other hand, slight rise i.e. $0.3 \%$ was observed among women who accomplished high school during the period of 2005 to 2016 . Women with primary school showed almost constant trend of unmet need for family planning over the periods of 11 years.

As birth order (parity) increases the proportion of unmet need for family planning also increases. In 2005 EDHS huge difference in unmet need was noticed between women having $1^{\text {st }}$ birth order and having 5 and above birth, which was $4.8 \%$ to $20.4 \%$ respectively. Similar pattern of difference was also occurred in 2016 EDHS i.e. $2.4 \%$ in first birth order and $13.8 \%$ in women having five and above birth history. Also, there has been similar drop in the prevalence of unmet need over the last 11 years in every categories of wealth quintile group.

\section{Decomposition analysis}

Table 3: summary of overall Decomposition Results of unmet need for family planning in Ethiopia 2005 to 2016 EDHS.

High outcome group: year==1 -- Low outcome group: year==0

\begin{tabular}{|lcccc|}
\hline Unmet need for family planning & Coefficient & p-value & $95 \% \mathrm{Cl}$ & percent \\
\hline E & -.014762 & 0.000 & $(-.0219,-.0076)$ & 8.93 \\
\hline R & -.15047 & 0.000 & $(-.1747,-.126)$ & 91.066 \\
\hline E = difference as a result of Endowment; C = difference as a result of coefficients; R = Residual \\
\hline
\end{tabular}

Table4: Decomposition of change in underweight among under five children in Ethiopia, 2005 to 2016. 
Characteristics Difference as a result of Characteristics (E)

Coefficient

\section{Age of respondents}

$15-24$

0

25-34

$-.0010019$

$-.00057132$

Percent

$35+$

\section{Respondent's educational status}

None

0

Primary

.004574

Secondary

Higher

.00013899

.0018623

\section{Wealth status}

Poor

0

Middle

.0003296

$-.00068838 *$

Rich

Age at marriage

$>=18$ years

0

$<18$ years

.001422

\section{Place of residency}

Urban

0

Rural

$-0.00010^{*}$

2.4612

$-.86062$

$-.19948$

0.41661

$-2.7682$

$-.084116$

$-1.1271$
Difference as a result of coefficient (C)

Coefficient

percent
0

$\begin{array}{ll}.016105 & -9.747 \\ .01105 & -6.6876\end{array}$

0

$.0097783 \quad-5.9179$

$\begin{array}{ll}.0090975^{*} & -5.5059\end{array}$

.0018788

$-1.1371$

\section{Birth order}

$1^{\text {st }}$

$2^{\text {nd }}$

$3^{\text {rd }}$

$4^{\text {th }}$

$5^{\text {th }} \&$ above

Desired no. of children

0
.000085443

.00070729

$-.00074^{*}$

.45165

5.101
0

.0013496

$-.81681$
3.8306

11.384

$-.018811$

11.384


$-.00023756$

.14378

$-.032901 * *$

19.912

\section{Perceived distance from health facility}

big problem

0

\begin{tabular}{lllll}
$\begin{array}{l}\text { Not big } \\
\text { problem }\end{array}$ & $-.010593 * * *$ & 6.4108 & -.01289 & 7.8013 \\
\hline Constant & - & - & -.1492 & 90.295
\end{tabular}

*: p-value $<0.05$, **: p-value $<0.01 \&$ ***: p-value $<0.001$

\section{Difference due to characteristics (Endowment)}

Generally, there have been decrement in unmet need for family planning among reproductive age group women in Ethiopia from 2005 to 2016. The multivariate decomposition analysis result showed that about $9 \%$ of change in unmet need for family planning among reproductive age group women was due to the difference in composition (endowment) the two surveys. Among the various important compositional factors, such as wealth index, birth order (parity), place of residence and perceived distance from health facility had a significant effect on unmet need for family planning among reproductive age group women.

A decrease in the composition of women with rich wealth index between 2005 and 2016 significantly contributed to the rise of unmet need for family planning by $0.41 \%$. Similarly, 2.5 percent increment in unmet need for family planning was due to decrease in the composition of women who reside in rural areas. Additionally, a decreased composition of women having birth order of four and birth order of five and above had significant impact in increasing unmet need for family planning among reproductive aged women by $0.45 \%$ and $5.15 \%$ respectively over the study period (2005-2016). And also, the decrement in composition of women who reported distance from health facility is not big problem showed significant contribution to positive change in unmet need for family planning i.e. rise of unmet need rate by 6.4 percent from 2005 to 2016.

\section{Difference due to effects of the coefficient}

Holding the effect of change in compositional characteristics constant, about nine in ten changes in unmet need for family planning was attributable to the difference in coefficients. This means, change in unmet need for family planning among reproductive-age women was due to difference in coefficient (effects of characteristics) across the two surveys.Factors that associated with the change of unmet need for family planning over the last 11 years were educational status, birth order, and desired number of children. Among these, high birth order made the largest contribution to the decrement of unmet need for family planning in the last 11 years, accounted more than one fourth changes [Coefficient $=0.04756$, $P<0.01]$. However, being a woman with less than five ideal number of desired children was the largest 
positive (increase) contributor through rising unmet need for family planning nearly by one fifth point percent $(20 \%)$. Women who had secondary education showed a significant negative contribution to the observed percentage decrease in unmet need for family planning over the study period which contributed about $5.5 \%$ with [Coefficient $=0.0092, \mathrm{P}<0.05$ ].

\section{Discussion}

The study demonstrated trend and explaining change of unmet need for family planning over the last 11 years i.e.2005 to 2016 EDHS. Consequently, trend of unmet need was significantly decreased by 16 point percentage over the last 11 years (2005 to 2016) among reproductive aged women in Ethiopia. Major change of the unmet need for family planning i.e.91\% over the decade was due to change in effect of covariates (coefficient) and the remaining $9 \%$ overall change was attributable to change of population composition (characteristics) of the two surveys.

Socio-demographic and obstetric factors like respondent's educational level, wealth status, place of residency, birth order and perceived distance from health facility were the contributory factors for the overall change of unmet need for family planning between 2005 and 2016. This finding Are in agreement with previous study done in Ethiopia and Pakistan $(23,24)$. For the decrement of unmet need over the last 11 years in Ethiopia, the implementation of health extension program all over the country take its lion's share, over the last decade Ethiopia showed improvement in accessibility and availability of health facilities and There is also documented evidence of improvement in autonomy in making decision for their own health $(25,26)$.

The results of this study suggest that rural residents (Table2) have had superior decline in unmet need for family planning compared to urban residents. This may be due to government dedication to raising rural community awareness related to maternal and child health and provision of healthcare facilities over the last decades.

From the decomposition analysis decrease in composition of women who reported distance to health facility is not big problem, who had five and more children, being rural dweller and women from rich wealth status contributes to compositional rise of unmet need for family planning. Decrease in composition of women of women who perceived distance from health facility as not big problem over the entire study period (2005-2016) shows significant effect on rise of unmet need for FP. This may be attributed to Ethiopia's improved health facilities in terms of physical accessibility and affordability in recent decades. In addition, specially trained community health workers have aided in the increased use of maternal health services such as family planning and health post were built nearby community (27).

Similarly, decreased composition of women who had five and above birth order results a sign significant impact on raise of unmet need for FP compared to women with only on birth order. Women with high number of children are more likely to face unmet need for FP Because of they have too many children and no fear of child death and reached the planned level of fertility. 
From 2005 to 2016 survey the compositional decrement of rural residence raised the unmet need for FP by $2.5 \%$ point percentage relative to urban resident. This can explained by speedy urbanization over the last decades (28). Urbanization was important in enhancing access to health facility and have a higher knowledge of maternal health service use than rural residents.

From change due to coefficient between the two surveys having secondary education, having many children and ideal number of children were significantly associated with the change of unmet need for FP. About 28\% decrease in unmet need for FP was attributable to women having 5 and above birth order. This finding is consistent with study done in Ethiopia(29).

Women who desired to have less than five number of children positively contributed to the rise of unmet need for family planning by $20 \%$ compared to women who desired greater than five number of children, a result that is consistent with other recent Ethiopian study (28). This can be explained by; women who desired to have less than five number of children more likely to face unmet need for FP to limit their number of children below five.

Other finding of this study was having secondary education contributed to decrease unmet need for FP by $5.5 \%$ point percentage, similar to what had been documented in other Ethiopian and Kenyan studies $(30,31)$. Women with a secondary education may have more access to knowledge about family planning, or formal education may have allowed them to better understanding of contraception (32). These educated women were also more likely to be more independent when it came to making contraceptive decisions(33). The findings of the study may inform maternal health programmers to strengthen home visit by health care workers to improve family planning uptake. This analysis did not consider program-related variables since only few of these variables were collected by the EDHS.

\section{Conclusion}

Remarkable change in unmet need for FP was observed between the period of 2005 and 2016. Both change in characteristics and coefficient were the contributing to observed change. Majority of the change in unmet need for FP was due to difference in coefficient over the study period. Mainly the change of unmet need for FP was due to change in women having birth order of five and above, having secondary education and women who desired number of children below five.

Empowering uneducated women about maternal health services specifically about family planning is required. The government and any concerned body could better focus on the enhancement of house hold economic status and health facility accessibility.

\section{Declarations}

\section{Conflict of Interest:}

No funding and no conflict of interest to declare. 


\section{References}

1. Gebre G, Birhan N, Gebreslasie K. Prevalence and factors associated with unmet need for family planning among the currently married reproductive age women in Shire-Enda-Slassie, Northern West of Tigray, Ethiopia 2015: a community based cross-sectional study. Pan African Medical Journal. 2016;23(1).

2. Bongaarts $\mathrm{J}$. The impact of family planning programs on unmet need and demand for contraception. Studies in Family Planning. 2014;45(2):247-62.

3. Westoff CF. The potential demand for family planning: a new measure of unmet need and estimates for five Latin American countries. International Family Planning Perspectives. 1988:45-53.

4. Alkema L, Kantorova V, Menozzi C, Biddlecom A. National, regional, and global rates and trends in contraceptive prevalence and unmet need for family planning between 1990 and 2015: a systematic and comprehensive analysis. The Lancet. 2013;381(9878):1642-52.

5. Ganatra B, Tuncalp O, Johnston HB, Johnson Jr BR, Gulmezoglu AM, Temmerman M. From concept to measurement: operationalizing WHO's definition of unsafe abortion. SciELO Public Health; 2014.

6. Sedgh G, Ashford LS, Hussain R. Unmet need for contraception in developing countries: examining women's reasons for not using a method. New York: Guttmacher Institute. 2016;2:2015-6.

7. Vahdaninia $M$. The unmet needs for modern family planning methods among postpartum women in Sub-Saharan Africa: a systematic review of the literature. 2021.

8. Wulifan JK, Jahn A, Hien H, Ilboudo PC, Meda N, Robyn PJ, et al. Determinants of unmet need for family planning in rural Burkina Faso: a multilevel logistic regression analysis. BMC pregnancy and childbirth. 2017;17(1):1-11.

9. Wemakor A, Garti H, Saeed N, Asumadu O, Anyoka B. Prevalence and determinants of unmet need for contraception in North Gonja District, Ghana. BMC women's health. 2020;20(1):1-9.

10. Nkoka O, Mphande WM, Ntenda PA, Milanzi EB, Kanje V, Guo SJ. Multilevel analysis of factors associated with unmet need for family planning among Malawian women. BMC public health. 2020;20:1-12.

11. Edietah EE, Njotang PN, Ajong AB, Essi MJ, Yakum MN, Mbu ER. Contraceptive use and determinants of unmet need for family planning; a cross sectional survey in the North West Region, Cameroon. BMC women's health. 2018;18(1):1-8.

12. Csa I. Central statistical agency (CSA)[Ethiopia] and ICF. Ethiopia demographic and health survey, Addis Ababa, Ethiopia and Calverton, Maryland, USA. 2016.

13. Austin A. Unmet contraceptive need among married Nigerian women: an examination of trends and drivers. Contraception. 2015;91(1):31-8.

14. Chafo K, Doyore F. Unmet need for family planning and associated factors among currently married women in Misha District, southern Ethiopia: a cross sectional study. J Women's Health Care. 2014;3(165):2167-0420.1000165. 
15. Gebreselassie T, Govindasamy P. Levels and trends in unmet need for family planning among adolescents and young women in Ethiopia: further analysis of the 2000, 2005, and 2011 Demographic and Health Surveys. DHS Further Analysis Report. 2013(72).

16. Sulthana B, Shewade HD, Sunderamurthy B, Manoharan K, Subramanian M. Unmet need for contraception among married women in an urban area of Puducherry, India. The Indian journal of medical research. 2015;141(1):115.

17. MacQuarrie K. Unmet need for family planning among young women: levels and trends: ICF International; 2014.

18. Mihret N. Magnitude and associated factors of unmet need for contraceptive methods among currently married women in west Belessa District. North Western Ethiopia. 2015;4(10):164-9.

19. Dejenu G, Ayichiluhm M, Abajobir AA. Prevalence and associated factors of unmet need for family planning among married women in Enemay District, Northwest Ethiopia: a comparative crosssectional study. Global J Med Res. 2013;13(4).

20. Bankole A, Hussain R, Sedgh G, Rossier C, Kaboré I, Guiella G. Unintended pregnancy and induced abortion in Burkina Faso: Causes and consequences. New York: Guttmacher Institute. 2014.

21. Okonofua FE, Odimegwu C, Ajabor H, Daru PH, Johnson A. Assessing the prevalence and determinants of unwanted pregnancy and induced abortion in Nigeria. Wiley Online Library; 1999.

22. Demographic E. Health Survey: Addis Ababa, Ethiopia and Calverton. Maryland, USA: Central Statistical Agency and ORC Macro. 2006.

23. Tadele A, Abebaw D, Ali R. Predictors of unmet need for family planning among all women of reproductive age in Ethiopia. Contraception and reproductive medicine. 2019;4(1):1-9.

24. Asif MF, Pervaiz Z. Socio-demographic determinants of unmet need for family planning among married women in Pakistan. BMC public health. 2019;19(1):1-8.

25. Woldemicael G, Tenkorang EY. Women's autonomy and maternal health-seeking behavior in Ethiopia. Maternal and child health journal. 2010;14(6):988-98.

26. Tesema GA, Yeshaw Y, Kasie A, Liyew AM, Teshale AB, Alem AZ. Spatial clusters distribution and modelling of health care autonomy among reproductive-age women in Ethiopia: spatial and mixedeffect logistic regression analysis. BMC Health Services Research. 2021;21(1):1-12.

27. Medhanyie A, Spigt M, Kifle Y, Schaay N, Sanders D, Blanco R, et al. The role of health extension workers in improving utilization of maternal health services in rural areas in Ethiopia: a cross sectional study. BMC health services research. 2012;12(1):1-9.

28. Tegenu T. Urbanization in Ethiopia: Study on growth, patterns, functions and alternative policy strategy. 2010.

29. Korra A. Attitudes toward family planning and reasons for nonuse among women with unmet need for family planning in Ethiopia: Citeseer; 2002.

30. Zenebe CB, Adefris M, Yenit MK, Gelaw YA. Factors associated with utilization of long-acting and permanent contraceptive methods among women who have decided not to have more children in 
Gondar city. BMC women's health. 2017;17(1):1-7.

31. Ontiri S, Ndirangu G, Kabue M, Biesma R, Stekelenburg J, Ouma C. Long-acting reversible contraception uptake and associated factors among women of reproductive age in rural Kenya. International journal of environmental research and public health. 2019;16(9):1543.

32. Radulović O, Šagrić Č, Višnjić A, Tasić A, Marković R. The influence of education level on family planning. Med Biol. 2006;13(1):58-64.

33. Acharya DR, Bell JS, Simkhada P, Van Teijlingen ER, Regmi PR. Women's autonomy in household decision-making: a demographic study in Nepal. Reproductive health. 2010;7(1):1-12.

\section{Figures}

unmet need of FP over time

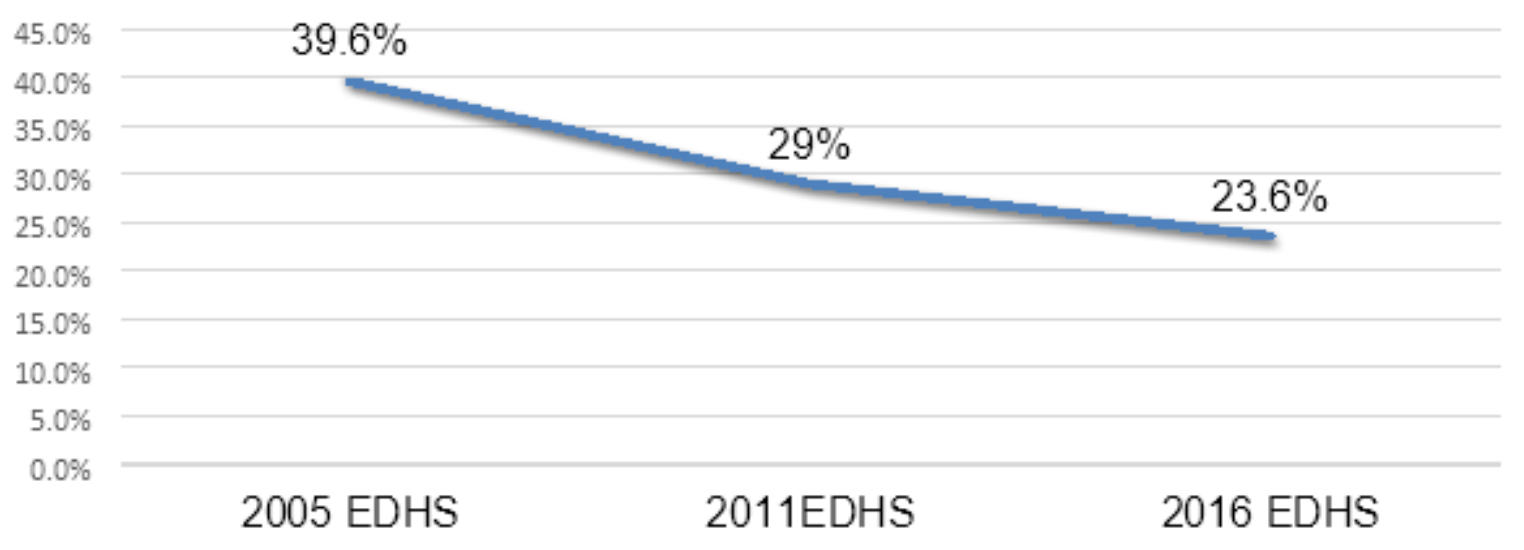

Figure 1

the trend in rate of unmet need of family planning among reproductive age women in Ethiopia in the past 11 years. 